\title{
Fish-mediated trait compensation in zooplankton
}

\author{
Samuel Hylander*,1, Maria Sol Souza², Esteban Balseiro ${ }^{2}$, Beatriz Modenutti ${ }^{2}$ and \\ Lars-Anders Hansson ${ }^{1}$
}

${ }^{1}$ Department of Biology and Aquatic Ecology, Lund University, Lund SE-223 62, Sweden; and ${ }^{2}$ INIBIOMA CONICET Univ. Nacl. Comahue, Lab. Limnol., RA-8400 San Carlos De Bariloche, Rio Negro, Argentina

\begin{abstract}
Summary
1. Environmental factors fluctuate spatially and temporally, and organisms that can alter phenotype in response to these changes may increase their fitness. Zooplankton are known to be able to induce body pigmentation in response to ultraviolet radiation (UVR) and to reduce the pigmentation when exposed to fish predators. Hence, reduced pigmentation because of the presence of fish could potentially lead to UVR damage, which calls for alternative protective mechanisms. 2. We exposed zooplankton to fish cues and UVR stress to assess whether body pigmentation and cellular antioxidants are flexible predation and UVR defences.

3. Zooplankton exposed to fish predator cues (no direct predation) reduced their pigmentation by c. $30 \%$ in 20 days. However, they were able to rapidly counteract negative UVR effects by increasing the activity of antioxidant defences such as glutathione $S$-transferase (GST). When exposed to UVR, the GST activity increased by $c .100 \%$ in zooplankton that had previously reduced their pigmentation because of fish cues. Transparency in the zooplankton did not lead to considerably higher UVR damage, here measured as inhibition of cholinesterase (ChE).

4. We conclude that zooplankton pigmentation and antioxidant enzymes are flexible UVR defence systems, which can be induced when needed. Zooplankton may employ antioxidant defences when pigmentation is reduced to counteract predation risk and thereby rapidly respond to detrimental effects of UVR exposure, that is, they can compensate one trait with another.
\end{abstract}

Key-words: carotenoids, cholinesterase, enzymes, glutathione $S$-transferase, oxidative stress, phenotypic plasticity, trait compensation, ultraviolet radiation, zooplankton

\section{Introduction}

Ultraviolet radiation (UVR) is an important environmental factor that may affect reproduction, survival and/or behaviour of several aquatic taxa, including zooplankton (e.g. Siebeck et al. 1994; Williamson et al. 1994; Leech \& Williamson 2000; Bancroft, Baker \& Blaustein 2007). UVR can affect biological systems at different scales, from direct DNA damage (Malloy et al. 1997) or photochemical reactions within cells producing reactive oxygen species (ROS; Yasui \& Sakurai 2000) to overall effects on zooplankton community composition (Williamson et al. 2001; Marinone 2006). To minimize these damages, zooplankton employ several different UVR protection strategies, including behavioural (vertical migration; Leech \& Williamson 2001; Rhode, Pawlowski \& Tollrian 2001) and physiological

*Correspondence author. Section of Ocean Ecology and Climate, National Institute for Aquatic Resources, Technical University of Denmark, Kavalergården 6, DK-2920 Charlottenlund, Denmark. E-mail:sahy@aqua.dtu.dk defences such as accumulation of UV-protective compounds (Hairston 1979; Sommaruga \& Garcia-Pichel 1999), as well as cellular defences like induction of antioxidants (Borgeraas \& Hessen 2000, 2002; Balseiro et al. 2008; Souza et al. 2010a,b) and cell repair systems (MacFadyen et al. 2004).

Vertical migration in response to UVR is widespread among cladocerans, for example, Daphnia sp. (Leech \& Williamson 2001; Rhode, Pawlowski \& Tollrian 2001; Hansson \& Hylander 2009b). Copepod zooplankton, which we focus on here, generally display much less vertical migration in response to UVR (Boeing et al. 2004; Hylander, Larsson \& Hansson 2009b). In any case, a certain water depth is needed to provide a UVR-free depth refuge. Physiological UVR defences entail accumulation of UVR-protective compounds such as carotenoids (Fig. 1), mycosporine-like amino acids (MAAs) and melanin (Hairston 1979; Hebert \& Emery 1990; Sommaruga \& Garcia-Pichel 1999). In addition to their photoprotective role, the carotenoids are strong antioxidants that function as neutralizers of photoproduced photosensitizers and singlet oxygen (Goodwin 1986; Palozza \& Krinsky 


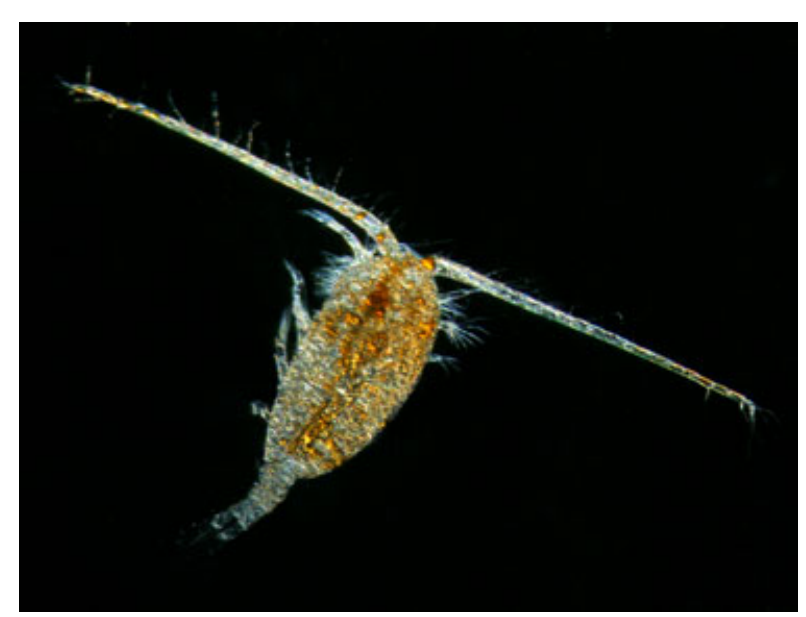

Fig. 1. A calanoid copepod with accumulated red carotenoids in the body tissues. The level of pigmentation is reduced if the copepod is exposed to fish cues. (Photo: Hans Berggren).

1992). Carotenoids are not produced by animals de novo and hence have to be incorporated from their food (Goodwin 1986; Andersson, Van Nieuwerburgh \& Snoeijs 2003). While pigmentation may increase upon UVR exposure, it can also be phenotypically reduced when zooplankton are exposed to predator cues (Hansson 2004; Hylander, Larsson \& Hansson 2009b; Hylander et al. 2009a). Pigmented zooplankton are more susceptible to predation than less-pigmented individuals (Luecke \& O'Brien 1981), and a trade-off between photoprotection and predation risk from fish has been proposed for both copepods (Hansson 2004) and Daphnia (Tollrian \& Heibl 2004). When predation and UVR threats are present at the same time, zooplankton mainly respond to the predation threat (Hylander, Larsson \& Hansson 2009b). This indicates that the threats are perceived on different scales, where the cost of predation is instant mortality, but UV damages act more slowly and may allow for reproduction (Hylander, Larsson \& Hansson 2009b).

Cellular UVR defences include cell repair and antioxidant enzyme systems (Borgeraas \& Hessen 2000, 2002; MacFadyen et al. 2004), and the latter, which hydrolyses ROS, can be generated within hours, and its activity may increase under UVR exposure (Borgeraas \& Hessen 2000, 2002; Balseiro et al. 2008). Among several different enzymes, glutathione $S$-transferase (GST) is a detoxifying enzyme known to be a key antioxidant enzyme for zooplankton that are exposed to UVR (Souza, Modenutti \& Balseiro 2007; Souza et al. 2010a,b), and its activity also depends on the food quality, so that low-quality food depresses the GST activity (Balseiro et al. 2008; Souza et al. 2010b). ROS are highly reactive towards cellular components and are likely to be disruptive to many cellular functions (Lopez-Mirabal \& Winther 2008), including enzymes such as cholinesterase (ChE; Forget, Beliaeff \& Bocquene 2003; Souza et al. 2010a). ChE hydrolyses acetylcholine (Ach), which is an important neurotransmitter in sensory and neuromuscular systems, vital for normal behaviour and muscular function (Forget, Beliaeff
\& Bocquene 2003). For example, ChE has been used as a biomarker for assessment of level of exposure to pesticides (Forget, Beliaeff \& Bocquene 2003; Kristoff et al. 2006). Hence, antioxidant enzymatic defences such as GST activity may represent the level of defence that the organism activates upon UVR exposure, and the ChE activity, which is a target on which UVR can exert detrimental effects, may be used as an estimate of the UVR damage (Souza et al. 2010a,b).

How all these UVR defence mechanisms work together will depend on the environmental setting. In cases of deep lakes, vertical migration may be the most important mechanism avoiding UVR threats (Leech \& Williamson 2001; Rhode, Pawlowski \& Tollrian 2001; Hansson \& Hylander 2009b), while photoprotection through pigments seems to be an important protection strategy in shallow fishless lakes, where vertical migration is not possible. The fact that copepods get rid of pigments like carotenoids when fish cues are present (Hylander, Larsson \& Hansson 2009b) leads to the hypothesis that cellular antioxidant enzymatic mechanisms are enhanced when both UVR and fish threats are present. In this study, we investigated whether the presence of fish cues under UVR exposure increases the cellular antioxidant enzymatic responses to avoid damage in sensitive molecules such as $\mathrm{ChE}$. We predicted that copepods would reduce their pigmentation when exposed to fish cues. Furthermore, in copepods with low pigmentation, we expected increased antioxidant defence activity (GST activity) reducing the UVR damage on sensitive molecules such as ChE. In other words, we predicted significant interactions between fish cues and UVR for GST activity, but not for ChE activity. For this purpose, we carried out experiments where we measured antioxidant response and cellular damage in the calanoid copepod Eudiaptomus gracilis at different body pigmentation and UVR exposure.

\section{Materials and methods}

The laboratory experiments were performed in Lund, Southern Sweden $\left(55 \cdot 7^{\circ} \mathrm{N}, 13 \cdot 5^{\circ} \mathrm{E}\right)$, to examine the interaction between levels of carotenoids and antioxidant enzymatic activities in copepods. Calanoid copepods (Eudiaptomus gracilis) were sampled from a nearby lake (Dalby quarry) by net hauls from the shore (mesh size: $300 \mu \mathrm{m}$ ). The quarry has a sparse fish population, it is about $10 \mathrm{~m}$ deep and has a $1 \%$ attenuation depth for UVA (at $380 \mathrm{~nm}$ ) of $1.3 \mathrm{~m}$ and UVB of $1.2 \mathrm{~m}$ (at $320 \mathrm{~nm}$ ). Copepods were transported in lake water to the laboratory and were allowed to acclimate to $12{ }^{\circ} \mathrm{C}$ for a couple of hours.

\section{PHASE 1}

During phase one (Fig. 2), tap water and c. 800 copepods were added to each of 10 cylindrical plastic UV opaque containers (height: $0 \cdot 19 \mathrm{~m}$; diameter: $0.21 \mathrm{~m}$; volume: $5 \mathrm{~L}$ ). The containers were illuminated by eight fluorescent lamps (36 W, UV-A-340, Q-Panel) mounted $0.1 \mathrm{~m}$ above the containers. Lamps were on at a $12: 12$ light/dark cycle, producing a UVA intensity of $6.5 \mathrm{~W} \mathrm{~m}^{-2}$ (sensor SUL240, IL1400A, International light) and a daily dose of $c$. $30 \mathrm{~J} \mathrm{~cm}^{-2}$ corresponding to a day during summer with some overcast (measured with the same sensors as above; Hylander, Larsson \& 


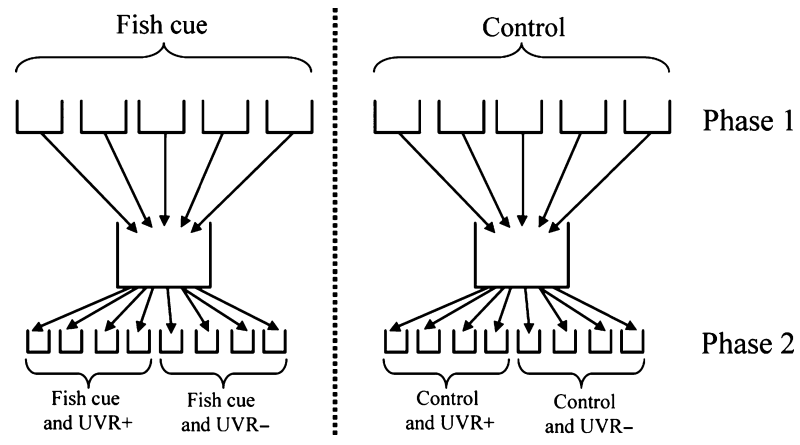

Fig. 2. Experiments were run in two phases. Phase one included two treatments that were run for 20 days $(n=5$; fish cue and control). One replicate failed in the fish cue treatment (see Methods) and had to be discarded before phase two. Phase two was run for $5 \mathrm{~h}$ and included four different treatments $(n=4$; fish cue and UVR $+=$ previous exposure to fish cues and UVR exposure; fish cue and UVR- = previous exposure to fish cues and non-UVR treatment; control and UVR $+=$ no previous fish cues and UVR exposure and, finally, control and UVR- $=$ no previous fish cues and no UVR exposure).

Hansson 2009b). These lamps are commonly used to simulate solar radiation in the UVR wavelength range (Hansson 2004; MacFadyen et al. 2004). For spectral composition, see Hansson, Hylander \& Sommaruga (2007). Copepods were fed with cultured phytoplankton (Scenedesmus sp. and Clamydomonas sp.). Five containers were assigned to fish cue treatment $(\mathrm{F})$, and five other containers were controls (C). Fish cue was produced by keeping $c$. 10 roach (Rutilus rutilus, $0+$ or $1+$; length, $50 \mathrm{~mm}$ ) in $8 \mathrm{~L}$ of water. Roach is a common fish in the study area, and zooplankton, including copepods, are one of the main prey items for this species, especially at fish sizes below 150 mm (Persson 1983; Hjelm, van de Weerd \& Sibbing 2003). Fish were fed with a zooplankton community from a nearby pond. After $24 \mathrm{~h}$, the fish were removed, and the water was filtered (GF/C, Whatman) and frozen in $25-\mathrm{mL}$ bottles $\left(-20^{\circ} \mathrm{C}\right)$. One such bottle was added every second day to the fish cue treatment (F). To the other containers (C), a similar bottle with frozen tap water was added at the same intervals. This method for producing fish cue has successfully been used in other studies (Hylander et al. 2009a). Experimental treatments during phase 1 (Fig. 2) were applied from 4 November 2010 until 24 November 2010. When terminating phase 1, copepods from each container (10-30 individuals) were collected for carotenoid analysis, and we used adults and later stages of copepodites, whereas egg-bearing females were always excluded. One replicate of the fish treatment failed because of high unexplained copepod mortality. There were not enough animals to conduct pigment analysis, and the replicate had to be discarded. Animals were kept in tap water for at least $1 \mathrm{~h}$ for gut evacuation and then measured at $40 \times$ magnification (Olympus SZ 40) before freezing at $-80^{\circ} \mathrm{C}$. UVR transparency was also quantified at the end of phase 1 by calculating the $1 \%$ attenuation depth at $320 \mathrm{~nm}$ using the relationship between the absorption coefficient $\left(A_{320}\right)$ and the diffuse attenuation coefficient (Kirk 1994; Morris et al. 1995). To obtain the absorption coefficient $\left(A_{320}\right)$, water samples from the containers were analysed for absorbance at $320 \mathrm{~nm}$ (Beckman DU 800 spectrophotometer).

\section{PHASE 2}

After sampling for carotenoids, all containers with fish cues in phase 1 were pooled in one large container, and similarly all control containers were pooled in another large container (Fig. 2). This procedure was applied to eliminate potential variance within previous treatments (i.e. fish cues or control). Copepods that had been exposed to fish cues were then distributed on a volume basis in equal amounts $(280 \mathrm{~mL})$ to eight containers similar to those described previously. Four of these containers were assigned to UVR treatment (fish cue and UVR+) and four to a non-UVR treatment (fish cue and UVR-). Likewise, copepods from the control treatment in phase 1 were treated in the same way (control and UVR+; control and UVR-). Copepods were then illuminated with the same fluorescent lamps as earlier for $5 \mathrm{~h}$ at a UVA intensity of $9.7 \mathrm{~W} \mathrm{~m}^{-2}$. Copepods in the non-UVR treatments (fish cue and UVR-; control and UVR-) were released from UVR exposure by the use of Plexiglas (Röhm GS 233), effectively cutting off most of the radiation below $370 \mathrm{~nm}$, that is, in the UVA and UVB range. In treatments that were exposed to UVR (fish cue and UVR+; control and $\mathrm{UVR}+$ ), radiation was permitted to enter treatments by use of UVR-transparent Plexiglas (Röhm GS 2458). There were no differences, however, in transmittance of photosynthetically active radiation (PAR) between Plexiglas types (Hansson, Hylander \& Sommaruga 2007). Hence, copepods in non-UVR treatments received only wavelengths above $370 \mathrm{~nm}$, whereas copepods in the UVR treatments were exposed to all wavelengths. After radiation exposure, all copepods were sampled and frozen at $-80{ }^{\circ} \mathrm{C}$. The mortality rate during the entire experiment was in the order of $5-8 \%$ per day, given the number of animals used for pigment and antioxidant analyses. This level of mortality is common during copepod experiments (Zeller, Jimenez-Melero \& Santer 2004; Hylander, Larsson \& Hansson 2009b).

\section{PIGMENT AND ANTIOXIDANT ANALYSIS}

Samples for carotenoid analysis were extracted in 1-2 $\mathrm{mL}$ of ethanol $(95 \%)$ for $1 \mathrm{~h}$ and were then disrupted using an ultrasonic converter (Heat Systems model CL4; Heat Systems, Farmingdale, New York, USA; $20 \mathrm{kHz}, 30 \mathrm{~s}$ ), followed by extraction in ethanol at room temperature for $5 \mathrm{~h}$ in the dark (Hylander, Larsson \& Hansson 2009b). The samples were centrifuged for $5 \mathrm{~min}$ at $503 \mathrm{~g}$. Quantification of the extracted red pigment in the supernatant was performed with a Beckman DU 800 spectrophotometer at $474 \mathrm{~nm}$, the absorption peak for common carotenoids in copepods, that is, astaxanthin and its esters (Hairston 1979; Hansson 2000). The samples were also scanned at $1-\mathrm{nm}$ resolution from 350 to $700 \mathrm{~nm}$. No peaks were observed at the absorption maximum of chlorophyll $(665 \mathrm{~nm})$, indicating that gut evacuation had been effective and that carotenoids from algae in the gut were not included in the analysis. The concentration of carotenoids was normalized to dry weight calculated from published relationships between length and dry weight for calanoid copepods (Bottrell, Duncan \& Gliwcz 1976). Other studies have analysed pigmentation level with help of digital photography (Vestheim \& Kaartvedt 2006), but here we applied extraction methods as the total amount of pigments are relevant for the level of UVR protection.

For antioxidant enzyme activity measurements, 30 individuals per replicate were homogenized using a glass-teflon homogenizer with ice-cold $50 \mathrm{~mm}$ potassium phosphate buffer, $\mathrm{pH} 7.7$ containing $1 \mathrm{~mm}$ EDTA and $0 \cdot 1 \%$ Triton X-100 according to Borgeraas \& Hessen (2000). Supernatants of homogenates were centrifuged for $10 \mathrm{~min}$ $\left(10000 \mathrm{~g} ; 4^{\circ} \mathrm{C}\right)$, and measurements of enzymatic activities were carried out using a Beckman DU 800 spectrophotometer. 
Total ChE activity was determined following the colorimetric method of Ellman et al. (1961), using acetylthiocholine iodide as substrate and dithiobisnitrobenzoate (DTNB) as reagent. ChE activity is expressed as $\mu$ mol product developed $\min ^{-1}$ [g protein $]^{-1}$.

Total GST activity was estimated following Habig, Pabst \& Jakoby (1974) in $100 \mathrm{~mm}$ phosphate buffer ( $\mathrm{pH} \mathrm{6.5),} \mathrm{with} 1 \mathrm{~mm}$ of 1-chloro-2,4-dinitrobenzene (CDNB) in acetonitrile $(1 \% \mathrm{v} / \mathrm{v})$ and GSH $1.2 \mathrm{~mm}$ as substrates recording the absorbance at $340 \mathrm{~nm}$. The specific activity of GST was expressed in nmol of product developed per minute per mg of protein (nmol prod $\mathrm{min}^{-1}[\mathrm{mg} \mathrm{prot}]^{-1}$ ) and is hereafter denoted GST activity. Protein determination was performed according to Lowry et al. (1951) with bovine serum albumin as a standard.

\section{STATISTICAL ANALYSIS}

Independent samples $t$-tests (two-tailed) and two-way ANOvAs were applied for results from phase 1 and 2, respectively (full factorial models including main effects and interactions). Multiple comparisons were also performed for two-way ANOvAs for interpretation of differences among all treatments (Tukey's test). The data met the assumptions of equal variance among groups (Levene's test: $F=1.9$, $P=0.18$ and $F=2 \cdot 5, P=0 \cdot 11$ for GST and ChE, respectively) and normal distribution (Kolmogorov-Smirnov test: $P=0.86$ and $P=0.54$ for GST and ChE, respectively). These data were also presented at different pigment levels (i.e. the mean values of pigment levels in fish or non-fish treatments; Fig. 6) to analyse the effect of UVR at different pigment levels. The significance level (alpha) was set at 0.05 , and all analyses were performed in SPSs 15.0 for Windows, and when necessary, data were logtransformed to meet the assumptions of the tests.

\section{Results}

\section{PHASE 1}

Copepod carotenoid content ranged from 3.6 to $4.7 \mu \mathrm{g} \mathrm{mg} \mathrm{DW}^{-1}$ after 20 days of exposure to fish cues and a control treatment. Levels were c. $30 \%$ lower in copepods that had been exposed to fish cues compared with the control (Fig. 3; $t=4 \cdot 9, P=0.01$, d.f. $=3 \cdot 6$ ). The $1 \%$ attenuation depth for UVB was $c .0 \cdot 6 \mathrm{~m}$ in both treatments (fish cue and control; $320 \mathrm{~nm}$ ), and there was no difference in UVR transparency between treatments $(t=1 \cdot 4, P=0 \cdot 21$, d.f. $=7)$.

\section{PHASE 2}

Copepods that had previously been exposed to fish cues or a control treatment (phase 1) displayed different responses in the antioxidant defences. The GST activity was generally high in the combined fish cue and UVR treatment (Fig. 4; fish cue and UVR +). All other treatments had lower and relatively similar GST activities (Fig. 4) resulting in a significant interaction between fish and UV (Table 1).

Depressed ChE activity, here used as a measurement of UVR damage, was observed in UVR + treatments (Fig. 5). Hence, there was a significant general negative effect of UVR exposure on ChE activity (Table 1). ChE activity in response to fish treatment and the interaction between fish and UVR

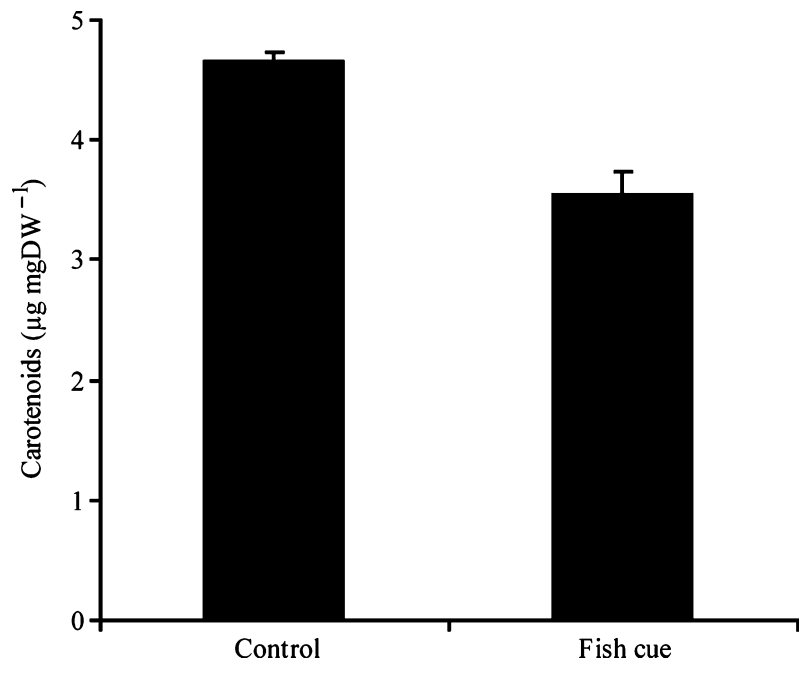

Fig. 3. Results from phase one in the experiment. Mean carotenoid content in copepods exposed to fish cues or to a non-fish treatment (i.e. control; $n=5$ ). Error bars denote $+1 \mathrm{SE}$.

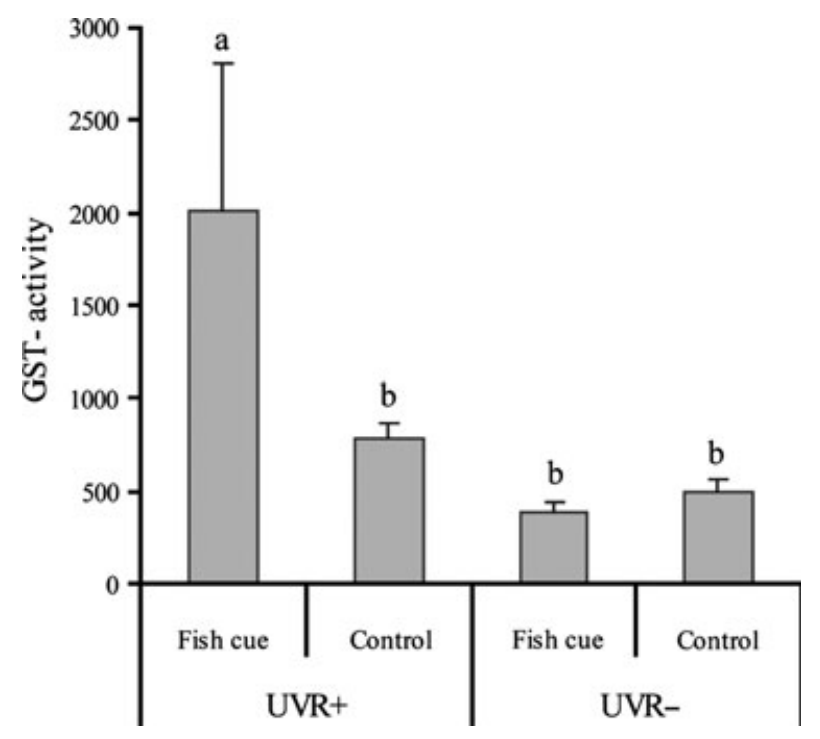

Fig. 4. Mean glutathione $S$-transferase activity (i.e. UVR defence) in copepods after experimental phase two. There were four different treatments including: fish cue and UVR +; fish cue and UVR-; control and UVR + ; and, finally, control and UVR-; $n=4$. Different letters denote treatments that are significantly different in multiple comparisons tests $(P<0 \cdot 05)$. Error bars denote $+1 \mathrm{SE}$.

were not significant (Table 1). Multiple comparisons revealed that ChE activity only differed upon UVR exposure in treatments that had previously been exposed to fish cues (Fig. 5). Synthesizing the data at different pigment levels (see methods), there was a strong response in GST activity at low pigmentation levels if animals were exposed to UVR (Fig. 6; high-low pigmentation, $F_{1,12}=1 \cdot 3, P>0.05$; high-low UVR, $\quad F_{1,12}=23.6, \quad P<0.05 ; \quad$ pigmentation $\times \mathrm{UVR}$, $\left.F_{1,12}=6.6, P<0.05\right)$. On the other hand, ChE activity did not show any marked depression at low carotenoid contents regardless of UVR level (Fig. 6; high-low UVR, $F_{1,12}=5 \cdot 0$, 
Table 1. Summary of the results for phase two (two-way ANOva). The fish factor represents previous presence or absence of fish cues (in phase one), and the UVR factor represents UVR or non-UVR treatment in phase two. Significant results are indicated with bold text

\begin{tabular}{lrrrlll}
\hline & \multicolumn{3}{c}{ GST } & & \multicolumn{2}{l}{ ChE } \\
\cline { 3 - 4 } \cline { 5 - 6 } Factor & d.f. & \multicolumn{1}{c}{$F$} & $P$-value & $F$ & $P$-value \\
\hline Fish & 1 & 1.3 & 0.278 & 2.6 & 0.132 \\
UVR & 1 & 23.6 & $<\mathbf{0 . 0 0 1}$ & 5.0 & $\mathbf{0 . 0 4 4}$ \\
Fish $\times$ UVR & 1 & 6.6 & $\mathbf{0 . 0 2 5}$ & $1 \cdot 1$ & 0.319 \\
Error & 12 & & & & \\
Total & 16 & & & & \\
\hline
\end{tabular}

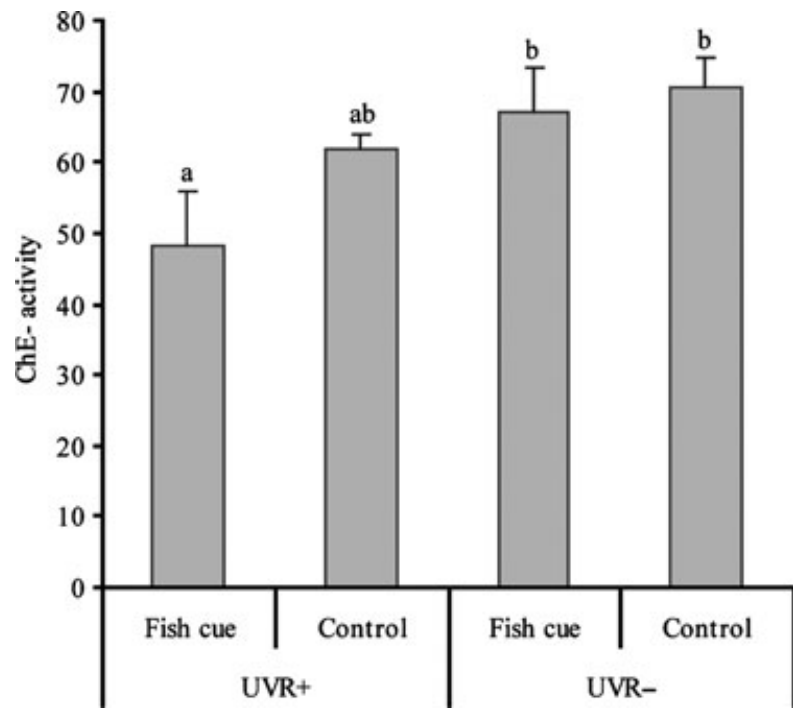

Fig. 5. Mean ChE activity (i.e. UVR damage) in copepods after experimental phase two. Inhibition of $\mathrm{ChE}$ activity is regarded as a sign of oxidative stress. There were four different treatments including: fish cue and UVR +; fish cue and UVR-; control and UVR + ; and, finally, control and UVR $-; n=4$. Different letters denote treatments that are significantly different in multiple comparisons tests $(P<0 \cdot 05)$. Error bars denote $+1 \mathrm{SE}$.

$P<0.05$; high-low pigmentation, $F_{1,12}=2 \cdot 6, P>0 \cdot 05$; pigmentation $\left.\times \mathrm{UVR}, F_{1,12}=1 \cdot 1, P>0 \cdot 05\right)$.

\section{Discussion}

Zooplankton have evolved a variety of defence mechanisms to meet changes in UVR, including vertical migration, pigmentation and antioxidant defences (Borgeraas \& Hessen 2000; Helbling \& Zagarese 2003; Hansson \& Hylander 2009a). Several of these defences may be phenotypically adjusted to the present situation. Hence, organisms may compromise among defences to optimize their behaviour and phenotype (Hansson, Hylander \& Sommaruga 2007). All defences are, however, not efficient in all systems, for example, vertical migration in shallow systems or pigmentation when fish predators are abundant. There are several examples of trait compensation between behavioural and morphological defences in different organisms including snails (Dewitt,
Sih \& Hucko 1999; Rundle \& Bronmark 2001) and zooplankton (Hansson, Hylander \& Sommaruga 2007), where one defence is up-regulated when another is reduced. The underlying assumption of trait compensation is that it is energetically costly to produce and maintain several defences at the same time (Pettersson \& Brönmark 1997), and thus, costly defences are reduced to less costly defences when possible (Mikolajewski \& Johansson 2004). Different zooplankton taxa tend to display dissimilar blends of antioxidant defences among systems and in response to UVR, including differences in catalase (CAT) and superoxide dismutase and GST activity (Borgeraas \& Hessen 2000, 2002; Souza, Modenutti \& Balseiro 2007). However, GST activity, but not CAT, has previously been shown to be a key antioxidant UVR defence in copepods (Souza, Modenutti \& Balseiro 2007; Souza et al. 2010a,b). Differences in type and strength of antioxidant responses have been suggested to be related to levels of photoprotective compounds in the zooplankton (Borgeraas \& Hessen 2000, 2002; Souza et al. 2010a). In Arctic amphipod species, a negative relationship has been observed between the amount of photoprotective compounds and UVRinduced antioxidant enzymatic response (Obermuller, Karsten \& Abele 2005). Here we demonstrate that zooplankton can compromise at other scales of response, balancing between level of pigmentation and antioxidant defences when challenged with UVR and visual predation risk. When copepods had been exposed to predator cues, they reduced their carotenoid pigmentation but instead, and supporting our predictions, induced higher level of GST activity (significant interaction between fish cues and UVR). Hence, there is also trait compensation in zooplankton between morphological (pigmentation) and cellular (antioxidant) defences.

Carotenoid pigmentation levels in zooplankton vary considerably among species and systems (Persaud et al. 2007; Hylander et al. 2009a; Hylander \& Jephson 2010; Sommaruga 2010). Levels increase upon UVR exposure (Hansson 2004; Moeller et al. 2005; Hylander, Larsson \& Hansson 2009b; Hylander et al. 2009a), but are reduced when zooplankton are exposed to predator cues (Hansson 2004; Hylander, Larsson \& Hansson 2009b; Hylander et al. 2009a). The actual mechanisms for how copepods reduce their pigmentation are not well known. Reductions could be linked to physiological changes or reduced feeding, and hence, lower pigment accumulation when predators (or cues) are present. Zooplankton can reduce their activity when exposed to predator cues (Weber \& Van Noordwijk 2002), but the potential pigmentation changes remain to be assessed. There are many examples in nature of predator cue-mediated responses where organisms change morphology to reduce predation, but at a cost of slower growth and reproduction (Tollrian \& Harvell 1999). Typical examples are fish that have evolved the ability to adjust body depth and amphibians that can grow large tails to reduce predation (Brönmark \& Miner 1992; Relyea 2001; Van Buskirk 2002). In natural systems, levels of carotenoids in zooplankton only tend to increase at increasing UV threat in low-predation systems (Hylander et al. 2009a). In our study, when zooplankton were exposed to 


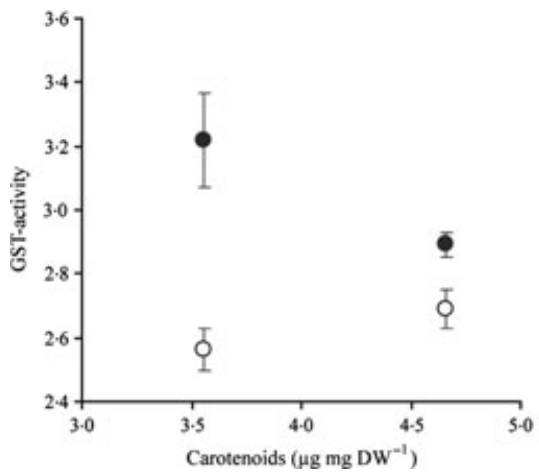

predator cues, they phenotypically reduced the pigmentation level by c. $30 \%$ in 20 days. In all, this suggests that carotenoids are costly in terms of increased predation risk. Pigmented specimens indeed suffer from higher predation mortality compared with transparent individuals (Luecke \& O'Brien 1981; Byron 1982; S. Hylander et al. unpublished data). When exposed to both UVR and predation threats, copepods tend to mostly respond to the predation threat by reductions in pigmentation (Hylander, Larsson \& Hansson 2009b), which indicates that other defences in high-predation systems have to be employed to avoid UVR damage.

Reduced pigmentation levels may be costly to the zooplankton as transparent animals show a lower radiation tolerance than pigmented specimens (Hairston 1976; Byron 1982). UVR may lead to direct DNA damage or photochemical reactions within cells producing ROS (Malloy et al. 1997; Yasui \& Sakurai 2000). ROS in turn have several detrimental effects including damage to proteins and fatty acids as well as DNA (Fuchs \& Packer 1991). Detectable changes in GST activity were present in our study, even though we only applied UVR treatment for $5 \mathrm{~h}$. This emphasizes the importance of antioxidant defences in high-predation systems when UVR exposure changes. Antioxidant defences can be particularly important for organisms during rapid changes in UVR (within hours), whereas the time lag for pigment accumulation (days) reduces its efficiency as a short-term defence mechanism (Souza et al. 2012).

ChE activity is a well-known biomarker used to assess environmental contaminants (Forget, Beliaeff \& Bocquene 2003; Kristoff et al. 2006), and it has also previously been shown to be a useful tool when quantifying UVR stress in copepods (Souza et al. 2010a). Therefore, we used the decrease in ChE activity as a measure of damage, to evaluate the success in defence compensation at the cellular level. Our results showed that although ChE activity was negatively affected by UVR, this reduction was not enhanced by the presence of fish cues, that is, by the reduction in carotenoid levels (as predicted no significant interaction between fish cues and UVR). These results indicate that the defence compensation observed with the increase in GST when both UVR and fish cues were present were enough to maintain protection in sensitive molecules such as ChE. This implies that this mechanism may also be successful in protecting other sensitive biochemical endpoints, such as DNA, proteins and unsaturated lipids, from
Fig. 6. Mean glutathione $S$-transferase activity (left panel) and $\mathrm{ChE}$ activity (right panel) at different levels of pigmentation and at UVR or non-UVR treatments (UVR + and UVR-). Pigmentation levels are mean values of fish and control treatments from Fig. 3, $n=4$. Error bars denote $+1 \mathrm{SE}$

the detrimental effect of ROS when carotenoids levels are reduced because of predation risk.

The negative effect of UVR on macromolecules such as ChE may be either caused by direct effects of radiation on the molecule (Bishop et al. 1980) or an indirect effect through UVR-generated ROS that in turn oxidize labile molecules (Lesser 2006; Souza et al. 2010a). Carotenoids protect organisms from UVR in both ways, as they act as sunscreen absorber (García-Pichel 1994), as well as ROS quencher (Lesser 2006). With the reduction in carotenoids induced by fish predation risk (Hylander et al. 2009a), both protective functions will be weakened. However, the observed increase in GST activity will compensate only for the ROS-quenching function. Based on this, it may be suggested that the reduction in ChE activity in the combined fish cue and UVR + treatment (Fig. 5) gives an estimate of the magnitude of this direct effect of UVR on ChE.

Given the relatively small sample size in this experiment, some caution should be taken when extrapolating the results. More extensive studies should be considered, for example, when the levels of GST and ChE activity are compared between laboratory and field samples. However, we conclude that copepod pigmentation and antioxidant defences are inducible interactive defences and that zooplankton reduced their pigmentation when exposed to fish cues. Furthermore, copepods increased their antioxidant defences upon UVR stress if they had previously reduced their pigmentation, suggesting that the copepods use trait compensation to cope with a constantly changing environment. The antioxidant defences reduced the negative effects of UVR so that individuals with lower pigmentation level still did not suffer from higher UVR stress compared with more pigmented copepods. Zooplankton employ a variety of UVR defences, and in addition to vertical migration and pigmentation, we here conclude that they can also use antioxidant defences to reduce negative effects of UVR. In a larger context we predict that organisms that are able to counteract UVR damages will increase their fitness compared with those without defence compensation, as UVR targets key components of the cell metabolism and the overall ability of the organism to survive.

\section{Acknowledgements}

The study was funded by the Swedish Research Council (VR) and by FONCyT PICT2007-1258 and CONICET from Argentina. The study complies with the 
current laws in Sweden; ethical concerns on care and use of experimental animals were followed under permission (M14-04) from the Malmö/Lund Ethical Committee.

\section{References}

Andersson, M., Van Nieuwerburgh, L. \& Snoeijs, P. (2003) Pigment transfer from phytoplankton to zooplankton with emphasis on astaxanthin production in the Baltic Sea food web. Marine Ecology-Progress Series, 254, 213 224.

Balseiro, E., Souza, M.S., Modenutti, B. \& Reissig, M. (2008) Living in transparent lakes: low food $\mathrm{P}: \mathrm{C}$ ratio decreases antioxidant response to ultraviolet radiation in Daphnia. Limnology and Oceanography, 53, 2383-2390.

Bancroft, B.A., Baker, N.J. \& Blaustein, A.R. (2007) Effects of UVB radiation on marine and freshwater organisms: a synthesis through meta-analysis. Ecology Letters, 10, 332-345.

Bishop, W.H., Henke, L., Christopher, J.P. \& Millar, D.B. (1980) Photodestruction of acetylcholinesterase. Proceedings of the National Academy of Sciences, 77, 1980-1982.

Boeing, W.J., Leech, D.M., Williamson, C.E., Cooke, S. \& Torres, L. (2004) Damaging UV radiation and invertebrate predation: conflicting selective pressures for zooplankton vertical distribution in the water column of low DOC lakes. Oecologia, 138, 603-612.

Borgeraas, J. \& Hessen, D.O. (2000) UV-B induced mortality and antioxidant enzyme activities in Daphnia magna at different oxygen concentrations and temperatures. Journal of Plankton Research, 22, 1167-1183.

Borgeraas, J. \& Hessen, D.O. (2002) Variations of antioxidant enzymes in Daphnia species and populations as related to ambient UV exposure. Hydrobiologia, 477, 15-30.

Bottrell, H.H., Duncan, A., Gliwicz, Z.M., Grygierek, E., Herzig, A., Hillbricht-Ilkowska, A., Kurasawa, H., Larsson, P. \& Weglenska, T. (1976) Review of some problems in zooplankton production studies. Norwegian Journal of Zoology, 24, 419-456.

Brönmark, C. \& Miner, J.G. (1992) Predator-induced phenotypical change in body morphology in crucian carp. Science, 258, 1348-1350.

Byron, E.R. (1982) The adaptive significance of calanoid copepod pigmentation - a comparative and experimental-analysis. Ecology, 63, 1871-1886.

Dewitt, T.J., Sih, A. \& Hucko, J.A. (1999) Trait compensation and cospecialization in a freshwater snail: size, shape and antipredator behaviour. Animal Behaviour, 58, 397-407.

Ellman, G.L., Courtney, K.D., Andres Jr, V. \& Featherstone, R.M. (1961) A new and rapid colorimetric determination of acetylcholinesterase activity. Biochemical Pharmacology, 7, 88-95.

Forget, J., Beliaeff, B. \& Bocquene, G. (2003) Acetylcholinesterase activity in copepods (Tigriopus brevicornis) from the Vilaine River estuary, France, as a biomarker of neurotoxic contaminants. Aquatic Toxicology, 62, 195-204.

Fuchs, J. \& Packer, L. (1991) Photooxidative stress in the skin. Oxidative Stress: Oxidants and Antioxidants (eds H. Sies), pp. 559-583. Academic Press, London.

García-Pichel, F. (1994) A model for internal self-shading in planktonic organisms and its implication for the usefulness of ultraviolet sunscreens. Limnology and Oceanography, 39, 1704-1717.

Goodwin, T.W. (1986) Metabolism, nutrition, and function of carotenoids. Annual Review of Nutrition, 6, 273-297.

Habig, W.H., Pabst, M.J. \& Jakoby, W.B. (1974) Glutathione $S$ transferases. The first enzymatic step in mercapturic acid formation. The Journal of Biological Chemistry, 249, 7130-7139.

Hairston, N.G. (1976) Photoprotection by carotenoid pigments in copepod Diaptomus-nevadensis. Proceedings of the National Academy of Sciences of the United States of America, 73, 971-974.

Hairston, N.G. (1979) Adaptive significance of color polymorphism in 2 species of Diaptomus (Copepoda). Limnology and Oceanography, 24, 15-37.

Hansson, L.A. (2000) Induced pigmentation in zooplankton: a trade-off between threats from predation and ultraviolet radiation. Proceedings of the Royal Society B: Biological Sciences, 267, 2327-2331.

Hansson, L.A. (2004) Plasticity in pigmentation induced by conflicting threats from predation and UV radiation. Ecology, 85, 1005-1016.

Hansson, L.A. \& Hylander, S. (2009a) Effects of ultraviolet radiation on pigmentation, photoenzymatic repair, behavior, and community ecology of zooplankton. Photochemical \& Photobiological Sciences, 8, 1266-1275.

Hansson, L.A. \& Hylander, S. (2009b) Size-structured risk assessments govern Daphnia migration. Proceedings of the Royal Society B: Biological Sciences, 276, 331-336.
Hansson, L.A., Hylander, S. \& Sommaruga, R. (2007) Escape from UV threats in zooplankton: a cocktail of behavior and protective pigmentation. Ecology, 88, 1932-1939.

Hebert, P.D.N. \& Emery, C.J. (1990) The adaptive significance of cuticular pigmentation in Daphnia. Functional Ecology, 4, 703-710.

Helbling, E.W. \& Zagarese, H. (eds). (2003) UV Effects in Aquatic Organisms and Ecosystems. The Royal Society of Chemistry, Cambridge.

Hjelm, J., van de Weerd, G.H. \& Sibbing, F.A. (2003) Functional link between foraging performance, functional morphology, and diet shift in roach (Rutilus rutilus). Canadian Journal of Fisheries and Aquatic Sciences, 60, 700-709.

Hylander, S. \& Jephson, T. (2010) UV protective compounds transferred from a marine dinoflagellate to its copepod predator. Journal of Experimental Marine Biology and Ecology, 389, 38-44

Hylander, S., Larsson, N. \& Hansson, L.A. (2009b) Zooplankton vertical migration and plasticity of pigmentation arising from simultaneous UV and predation threats. Limnology and Oceanography, 54, 483-491.

Hylander, S., Boeing, W.J., Graneli, W., Karlsson, J., von Einem, J., Gutseit, K. \& Hansson, L.A. (2009a) Complementary UV protective compounds in zooplankton. Limnology and Oceanography, 54, 1883-1893.

Kirk, J.T.O. (1994) Optics of UV-B radiation in natural waters. Ergebnisse der Limnologie, 43, 1-16.

Kristoff, G., Guerrero, N.V., Pechén de D' Angelo, A.M. \& Cochón, A.C. (2006) Inhibition of cholinesterase activity by azinphos-methyl in two freshwater invertebrates: Biomphalaria glabrata and Lumbriculus variegatus. Toxicology, 222, 185-194.

Leech, D.M. \& Williamson, C.E. (2000) Is tolerance to UV radiation in zooplankton related to body size, taxon, or lake transparency? Ecological Applications, 10, 1530-1540.

Leech, D.M. \& Williamson, C.E. (2001) In situ exposure to ultraviolet radiation alters the depth distribution of Daphnia. Limnology and Oceanography, 46, 416-420.

Lesser, M.P. (2006) Oxidative stress in marine environments: biochemistry and physiological ecology. Annual Review of Physiology, 68, 253-278.

Lopez-Mirabal, H.R. \& Winther, J.R. (2008) Redox characteristics of the eukaryotic cytosol. Biochimica et Biophysica Acta (BBA)-Molecular Cell Research, 1783, 629-640

Lowry, O.H., Rosenbrough, N.J., Farr, A.L. \& Randall, R.J. (1951) Protein measurement with the Folin phenol reagent. The Journal of Biological Chemistry, 193, 265-275.

Luecke, C. \& O'Brien, W.J. (1981) Photo-toxicity and fish predation - selective factors in color morphs in Heterocope. Limnology and Oceanography, 26, 454-460.

MacFadyen, E.J., Williamson, C.E., Grad, G., Lowery, M., Jeffrey, W.H. \& Mitchell, D.L. (2004) Molecular response to climate change: temperature dependence of UV-induced DNA damage and repair in the freshwater crustacean Daphnia pulicaria. Global Change Biology, 10, 408-416.

Malloy, K.D., Holman, M.A., Mitchell, D. \& Detrich, H.W. (1997) Solar UVB-induced DNA damage and photoenzymatic DNA repair in Antarctic zooplankton. Proceedings of the National Academy of Sciences of the United States of America, 94, 1258-1263.

Marinone, M. C., Menu Marque, S., Añón Suárez, D., Diéguez, M. D. C., Pérez, P., De Los Ríos, P., Soto, D. \& Zagarese, H. E. (2006) UV radiation as a potential driving force for zooplankton community structure in Patagonian lakes. Photochemistry and Photobiology, 82, 962-971.

Mikolajewski, D.J. \& Johansson, F. (2004) Morphological and behavioral defenses in dragonfly larvae: trait compensation and cospecialization. Behavioral Ecology, 15, 614-620.

Moeller, R.E., Gilroy, S., Williamson, C.E., Grad, G. \& Sommaruga, R. (2005) Dietary acquisition of photoprotective compounds (mycosporine-like amino acids, carotenoids) and acclimation to ultraviolet radiation in a freshwater copepod. Limnology and Oceanography, 50, 427-439.

Morris, D.P., Zagarese, H., Williamson, C.E., Balseiro, E.G., Hargreaves, B.R., Modenutti, B., Moeller, R. \& Queimalinos, C. (1995) The attentuation of solar UV radiation in lakes and the role of dissolved organic carbon. Limnology and Oceanography, 40, 1381-1391.

Obermuller, B., Karsten, U. \& Abele, D. (2005) Response of oxidative stress parameters and sunscreening compounds in Arctic amphipods during experimental exposure to maximal natural UVB radiation. Journal of Experimental Marine Biology and Ecology, 323, 100-117.

Palozza, P. \& Krinsky, N.I. (1992) Antioxidant effects of carotenoids invivo and invitro - an overview. Methods in Enzymology, 213, 403-420.

Persaud, A.D., Moeller, R.E., Williamson, C.E. \& Burns, C.W. (2007) Photoprotective compounds in weakly and strongly pigmented copepods and cooccurring cladocerans. Freshwater Biology, 52, 2121-2133. 
Persson, L. (1983) Food-consumption and the significance of detritus and algae to intraspecific competition in Roach Rutilus-rutilus in a shallow eutrophic lake. Oikos, 1, 118-125.

Pettersson, L.B. \& Brönmark, C. (1997) Density-dependent costs of an inducible morphological defense in Crucian carp. Ecology, 78, 18051815 .

Relyea, R.A. (2001) Morphological and behavioral plasticity of larval anurans in response to different predators. Ecology, 82, 523-540.

Rhode, S.C., Pawlowski, M. \& Tollrian, R. (2001) The impact of ultraviolet radiation on the vertical distribution of zooplankton of the genus Daphnia. Nature, 412, 69-72.

Rundle, S.D. \& Bronmark, C. (2001) Inter- and intraspecific trait compensation of defence mechanisms in freshwater snails. Proceedings of the Royal Society B: Biological Sciences, 268, 1463-1468.

Siebeck, O., Vail, T.L., Williamson, C.E., Vetter, R., Hassen, D., Zagarese, H., Little, E., Balseiro, E., Modenutti, B., Seva, J. \& Shumate, A. (1994) Impact of UV-B radiation on zooplankton and fish in pelagic freshwater ecosystems. Archiv fur Hydrobiologie Beihefte Ergebnisse der Limnologie, 43, 101-114.

Sommaruga, R. (2010) Preferential accumulation of carotenoids rather than of mycosporine-like amino acids in copepods from high altitude Himalayan lakes. Hydrobiologia, 648, 143-156.

Sommaruga, R. \& Garcia-Pichel, F. (1999) UV-absorbing mycosporine-like compounds in planktonic and benthic organisms from a high-mountain lake. Archiv für Hydrobiologie, 144, 255-269.

Souza, M.S., Modenutti, B.E. \& Balseiro, E.G. (2007) Antioxidant defences in planktonic crustaceans exposed to different underwater light irradiances in Andean lakes. Water, Air, \& Soil Pollution, 183, 49-57.

Souza, M.S., Balseiro, E., Laspoumaderes, C. \& Modenutti, B. (2010a) Effect of ultraviolet radiation on aetylcholinesterase activity in freshwater copepods. Photochemistry and Photobiology, 86, 367-373.

Souza, M.S., Modenutti, B.E., Carrillo, P., Villar-Argaiz, M., MedinaSánchez, J.M., Bullejos, F. \& Balseiro, E.G. (2010b) Stoichiometric dietary constraints influence the response of copepods to ultraviolet radiation-induced oxidative stress. Limnology and Oceanography, 55, $1024-1032$.
Souza, M.S., Hansson, L.-A., Hylander, S., Modenutti, B. \& Balseiro, E. (2012) Rapid enzymatic response to compensate UV radiation in Copepods. PLoS One, In press.

Tollrian, R. \& Harvell, C.D. (1999) The Ecology and Evolution of Inducible Defences. Princeton University Press, Princeton. New Jersey.

Tollrian, R. \& Heibl, C. (2004) Phenotypic plasticity in pigmentation in Daphnia induced by UV radiation and fish kairomones. Functional Ecology, 18, 497-502.

Van Buskirk, J. (2002) A comparative test of the adaptive plasticity hypothesis: relationships between habitat and phenotype in anuran larvae. American Naturalist, 160, 87-102.

Vestheim, H. \& Kaartvedt, S. (2006) Plasticity in coloration as an antipredator strategy among zooplankton. Limnology and Oceanography, 51, 1931-1934.

Weber, A. \& Van Noordwijk, A. (2002) Swimming behaviour of Daphnia clones: differentiation through predator infochemicals. Journal of Plankton Research, 24, 1335-1348.

Williamson, C.E., Zagarese, H.E., Schulze, P.C., Hargreaves, B.R. \& Seva, J. (1994) The impact of short-term exposure to UV-B radiation on zooplankton communities in North Temperate Lakes. Journal of Plankton Research, 16, 205-218.

Williamson, C.E., Olson, O.G., Lott, S.E., Walker, N.D., Engstrom, D.R. \& Hargreaves, B.R. (2001) Ultraviolet radiation and zooplankton community structure following deglaciation in Glacier Bay, Alaska. Ecology, 82, 17481760.

Yasui, H. \& Sakurai, H. (2000) Chemiluminescent detection and imaging of reactive oxygen species in live mouse skin exposed to UVA. Biochemical and Biophysical Research Communications, 269, 131-136.

Zeller, M., Jimenez-Melero, R. \& Santer, B. (2004) Diapause in the calanoid freshwater copepod Eudiaptomus graciloides. Journal of Plankton Research, 26, 1379-1388.

Received 7 July 2011; accepted 31 January 2012

Hanlding Editor: Jonathan Blount 